\title{
Management of Primary Dysmenorrhoea by Dry Cupping and Herbal Unani Drug.
}

\author{
*Kaenat Zahra ${ }^{1}$, Abdullah ${ }^{2}$, Razia Shaheen ${ }^{3}$ \\ 1.Dept of AmrazNiswan Wa Qabalat, Sufiya Medical College \& Research Centre, Chakia, \\ Motihari., \\ 2.Dept. Dept. of AmrazNiswan Wa Qabalat, Deoband Unani Medical College \& Research \\ Centre, Saharanpur, UP, India. \\ 3.Ilmul Advia, Govt. Tibbi College \& Hospital, Kadam Kuan, Patna, Bihar.
}

\begin{abstract}
Primary dysmenorrhea is a common menstrual cramps with high prevalence rate is responsible for the highest incidence of absenteeism resulting in loss of working hours. Thus, proper treatment is essential to over the hardship, the objective of this study is to evaluate the efficacy of Dry Cupping with Herbal Unani drug in the management of Primary Dysmenorrhoea. A randomized, standard controlled clinical trial was conducted in OPD of Deoband Unani Medical College \& Research Centre (DUMCH-RC),Saharanpur, UPfrom August 2014 to February 2016. Diagnosed case of primary dysmenorrhoea aged between 1230 years were included. A total of 60 subjects were assigned randomly to the interventions. The test group A $(\mathrm{n}=20)$ received $3 \mathrm{gm}$ of herbal drug namely hulba(Trigonella foenumgraecum) twice daily from day 1 to day 3 of menstrual cycle. The test group $B(n=20)$ received same dose of hulba with dry cupping. For hijamah three medium cups were applied below the umbilicus for 15 minutes on day 1 and day 3 of menstruation. Group $C(n=20)$ is controlled group which received standard drug mefanamic acid, $500 \mathrm{mg}$ twice daily for same duration as the test drug. These interventions were given for three consecutive cycles. The results were analyzed and compared statistically by using Analysis of variance (ANOVA), Chi-square or Fisher Exact test to find the significance of study parameters. The inter group comparison showed that group A was equally effective as group $\mathrm{B}$ and $\mathrm{C}(\mathrm{P}>0.05)$, whereas group $\mathrm{B}$ was more- effective than group $\mathrm{C}(\mathrm{P}=0.02)$ in reducing pain intensity. The associated symptoms were also improved in all groups. No adverse drug effects were observed. Dry cupping with hulba was more effective than mefanamic acid in reducing pain intensity and discomfort. Overall improvement were also observed in other associated symptoms. The dry cupping with hulba were found to be more effective in the management of primary dysmenorrhoea.
\end{abstract}

Keywords: Primary dysmenorrhoea; Hulba; Dry Cupping; VAS; Usre Tams Ibtedai.

*Corresponding Author Email: kaenatzahra@gmail.com

Received 12 November 2019, Accepted 22 November 2019

Please cite this article as: Zahra K et al., Management of Primary Dysmenorrhoea by Dry Cupping and Herbal Unani Drug.. American Journal of Pharmacy \& Health Research 2019. 


\section{INTRODUCTION}

According to Unani physicians, dry cupping below the umbilicus relieves dysmenorrhoea, especially in young girls. ${ }^{12,3}$ It works on the principle of imalaemawad (Diversion/shurtting of morbid matter/fluid) from the affected area. ${ }^{4}$ There is some evidence that cupping is effective in the treatment of painful conditions like osteoarthritis of knee 'joint or low back pain. Dry cupping therapy appears to have a role in the management of pain from dysmenorrhoea which is currently dominated by pharmaceutical and some surgical treatments. Dry cupping` offers a noninvasiveapproach, no side effects and no potential for drug interactions.

Though, hulba and dry cupping are in use since long time for dysmenorrhoea, but validation and documentation are not available till date. Therefore a Prospective, single center, open labeled, simple randomized standard controlled, pre and post evaluation trial was conducted on sixty subjects to prove efficacy and safety of hulba and dry cupping. The research question was whether hulba and dry cupping are effective in primary dysmenorrhoea and its associated symptoms. The hypothesis was the use of hulba in one group, hulha with dry cupping in other group in woman with primary dysmenorrhoea compared with standard drug would at 1, 2, 3, 4 months from the baseline to be effective at reducing severity of dysmenorrhoea and overall improvement in other symptoms associated with it. The primary outcome of this interventional study was evaluation of the efficacy and safety of hulba and dry cupping on the intensity of pain with well validated Visual Analogue Scale for pain intensity. Safety of the test drug was evaluated by clinical examination and biochemical tests. The secondary outcome was to assess the efficacy of test drug and dry cupping on associated symptoms (headache, nausea, vomiting, fatigue, and anxiety). For subjective assessment, the level of pain and other secondary variables were determined by using a four point rating scale: Grade 0 indicated no pain; grade 1, mild; grade 2, moderate; and grade 3 , severe with an assumption that this intervention will be effective in relieving pain and other symptoms. ${ }^{5}$

The results were analyzed and compared statistically by using Analysis of variance (ANOVA) to find the significance of study parameters between three groups of patients. Chi-square/Fisher Exact test has been used to find the significance of study parameters on categorical scale between three groups. The level of significance was 5\% and 95\% Confidence Interval has been computed to find the significant features.

Effectiveness of Unani drugs and regimental therapies in dysmenorrhoea are still under investigation and need more careful studies. Further, trial should examine a range of short term 
analgesia and longer outcomes like improvement in quality of life by using well validated health related quality of life questionnaire. However, any attempt to find treatments for dysmenorrhoea with less adverse effects is highly desired.

\section{Aims and Objectives}

The objectives of this present study were

1. To evaluate the efficacy and safety of dry cupping with Hulba and in the management of Primary dysmenrrhoea

2. To study the various clinical aspects of Primary dysmenrrhoea in the light of classical Unani literature

3. To compare the results statistically with standard control

Primary dysmenrrhoea is known as Usre Tams Ibtedai which means painful menstruation where bleeding is usually scanty and Viscouss. ${ }^{617}$ Most of the ancient Unani Physicians described the term Dysmenorrhoea under the heading of aujae rehm' that is pain of uterine origin. ${ }^{1,8}$ It appears that they had sound knowledge of this condition, and mentioned their personal experiences under various headings, like sue mizaj mukhtalif, ghaleez balgham wa sauda, reeh, ihtabase tams, warme rehm, ${ }^{8}$ insadade fame rehm, dabeela, sailane khoon, sailanemani, ikhtenaqurrehm and complications of some kidney and liver diseases etc. ${ }^{1}$

\section{Burden of Dysmenorrhoea}

Because young women constitute a significant percentage of the adult work force in the United States, about 600 million working hours, ${ }^{9}$ or 2 billion dollars are lost annually because of incapacitating Dysmenorrhoea, if adequate relief is not provided ${ }^{10}$ from 1-2 days absenteeism from a month, ${ }^{11}$ as a result of primary

Dysmenorrhoea. It has been estimated to cause the loss of 140,000,000 work hour's annually." Women who continue to work or to attend classes have been shown to have lower work output or scores during their Dysmenorrhoea. ${ }^{10}$ In consequence, it is associated with emotional, social and economic burdens. ${ }^{12}$

\section{Dry Cupping in Primary dysmenrrhoea}

Dry cupping is widely discussed therapeutic regimen in Unani classical literature. It is an ancient and universal practice that spans both East and West. In the East, the Chinese have been practicing the art of cupping for at least three thousand years. They apply the cups to the acupressure points to relieve the stagnation of Qi and blood, both locally and in the organs activated by the point. ${ }^{13}$ In the West, cupping therapy had its birth in Egypt. The Eberus Papyrus, written around 1500 B.C.E., states that bleeding by wet cupping removes foreign matter from the 
body. In cupping, the ancient Egyptians saw the remedy for just about every disorder. Cupping is now an important and popular therapeutic modality of Unani system. After falling out of favor with medicine in the modern era, cupping therapy is enjoying resurgence in popularity, Promoted by acupuncturists and other holistic healthcare practitioners. ${ }^{13}$

In Unani classical literature hukma have been indicating its use for various diseases. According to them diseases are due to the disproportionate distribution of humors or akhlat. These humors which are out of proportion collect in various parts of the body at times producing inflammation and leading to presentation of various diseases. ${ }^{14}$

Cupping is the application of suction cups to the skin, where vacuum is created in the cups causing the skin to rise in the cups and seal it against the skin to draw out the stagnant congested blood and vital force, as well as other stagnant or morbid humors. ${ }^{15}$ there are two types of cupping; dry and wet (Hijamah). Dry cupping. Which is done using suction pump or manual suction is used to create a vaccum. ${ }^{16}$

Pain is the essence of disease. Suffering, or disease, is experienced when things are not flowing right, when there is some difficulty or obstruction to the natural flow and functions of the body. This is what Jalinoos meant when he spoke of the disease as being the state contrary to nature. ${ }^{13}$ cupping also disperses pathogenic heat, toxins in order to relieve congestion and restore health.

Cupping works according to the principle of imala e mawad (Diversion of fluid) i.e., evacuation of morbid matter away from the affected area whether at' downwards or upward the body, likewise from inside towards periphery and vice versa or diverting inflammatory matter from an important organ to an organ of less importance. ${ }^{17 \cdot 18}$ Further they have described that accumulation of matter occurs in an organ, when it is weak or unable to prevent the accumulation of matter. If diversion of matter is not done, further accumulation may lead to various disorders. Toxins, morbid humors and other congested offending matter can do more harm when they are situated deep inside the body, their by interfering the functions of vital organs. The body however tries to peripheralize such morbid matter in the form of various cysts, boils or eruptions etc. Cupping is a way of activating this peripheralization and relieving pathogenic congestion, thus averting or preventing more serious complications. ${ }^{13,17}$

Traditional healers have long recognized the association between pain and conditions of congestion, stagnation and blockage. An age old Chinese medical maxim states: where there's stagnation, there will be pain. Remove the stagnation and remove the pain. Stagnation 
and congestion blocks the energies like vital force, vital fluids and humors like blood, lymph etc. The suction applied by cupping sucks out and breaks up congestion, stagnation or blockage, restoring a free flow to the vital energies and humors. ${ }^{13}$

The suction applied by cupping sucks out and breaks up that congestion, stagnation or blo $\&$ age, restoring a free flow to the vital energies and humors. In addition to the dispersing and breaking up the stagnation and congestion in the flow of the vital force and other humors, cupping also disperses pathogenic heat, toxins and inflammation by bringing them to the surface for release. By improving circulation of blood, lymph and other vital fluids, breaking up and dispersing blockages sand congestions of offending waste matter, toxins and morbid humors, cupping improves the eliminative functions and the evacuation of wastes from the organ $^{7}$ Dry cupping below the umbilicus relieves Dysmenorrhoea, especially in young girls. $3,19,20$

The benefits of cupping are many; it improves the circulation of blood and lymph. It also regulates and improves the functioning of the autonomic nervous system. The most obvious benefits of cupping are relief of pain and relaxation of stiff tendons and muscles. Cupping increases the cleansing flow of lymph, while removing congested blood from the muscles. By improving the blood flow cupping enhances the cleansing and removal of toxins. ${ }^{13}$

\section{MATERIALS AND METHOD}

A randomized, standard controlled clinical trial was conducted in OPD of Deoband Unani Medical College \& Research Centre (DUMCH-RC),Saharanpur, UP from August 2014 to February 2016. Diagnosed case of primary dysmenorrhoea aged between 12-30 years were included. A total of 60 subjects were assigned randomly to the interventions. The test group A $(\mathrm{n}=20)$ received $3 \mathrm{gm}$ of herbal drug namely hulba(Trigonella foenum graecum) twice daily from day 1 to day 3 of menstrual cycle. Subjects were divided into three equal groups with aid of simple randomization done by computer generated random list by Graph Pad Software Quickcalcs. The test group B $(n=20)$ received same dose of hulba with dry cupping. For dry cupping three medium cups were applied below the umbilicus for 15 minutes on day 1 and day 3 of menstruation. Group $\mathrm{C}(\mathrm{n}=20)$ is controlled group which received standard drug mefanamic acid, $500 \mathrm{mg}$ twice daily for same duration as the test drug. These interventions were given for three consecutive cycles. The results were analyzed and compared statistically by using Analysis of variance (ANOVA), Chi-square or Fisher Exact test to find the significance of study parameters. 
Study Design: Simple randomized standard controlled trial

Duration of Study: 1year and 6 months

\section{Criteria for Selection of Subjects:}

\section{Inclusion Criteria:}

1. Subjects aged 12-30 years having regular menstrual cycle (28 \pm 7 days)

2. Nulliparus and pares subjects with the history of primary dysmenorrhoea

\section{Exclusion Criteria:}

1. Subjects with congenital anomalies of uterus, secondary dysmenorrhoea, any organic pelvic pathology and membranous dysmenorrhoea

2. Subjects with any systemic illness like hypertension, diabetes mellitus, thyroids function, cardiovascular and renal diseases

3. Subjects on oral contraceptives or other hormonal agents

Sample Size: Total 60 subjects (20 in each group)

Group A: Test drug

Group B: Test drug with dry cupping

Group C: $\quad$ Standard drug

\section{Method of Collection of Data:}

By clinical examination, Visual Analogue Scale for pain intensity and investigations.

Procedure: A total of 60 eligible subjects, aged 12-30 years with painful menstruation for at least six months who provided informed consent were randomized and selected on the basis of clinical diagnosis.

During the selection procedure complete history and investigations were carried out, which was recorded on a prescribed case record form. (Annexure I) The subjects were enquired about their name, age, sex, marital status, menstrual history, parity and address. The chief complaints, duration of suffering in detail were noted in chronological order. Subjective assessment of as sociated symptoms (fatigue, headache, anxiety, nausea and vomiting) were done before and after the trial on the basis of 4 point scale $(0=$ none, $1=$ mild, $2=$ moderate, $3=$ severe).

Emphasis was also given on family history of dysmenorrhoea, past history of taking medications for dysmenorrhoea, and other gynecological and systemic disorders. Dietary and other habits were inquired in personal history. In socioeconomic history, 
Subjects were inquired about their monthly income, education and occupation, which were assessed by Kuppuswamy's Socioeconomic Scale. (Annexure II) The mizaj was assessed by using temperamental scale (on the basis of alamateajnaseashra) as described by ancient Unani physicians. (Annexure III). General, physical and systemic examination (including pelvic examination only in married women) was conducted to exclude general and systemic diseases respectively.

\section{Diagnostic Criteria:}

Pain in dysmenorrhoea was objectively assessed by colored Visual Analogue Scale (VAS) for pain. The test retest reliability of VAS for pain intensity was 0.896. "Baseline VAS score was taken before starting the treatment and were assessed at every follow up for four consecutive cycles.

The colored Visual Analogue Scale for pain intensity was graded as:

$0-1$ (Green Color) : $\quad$ No pain to distress

2-4 (Greenish Yellow) : : Annoying to uncomfortable

4-6 (Yellow) : Uncomfortable to dreadful

6-8 (Yellowish red) : : Dreadful to horrible

8-10 (Red) : : Horrible to agonizing (Annexure IV)

\section{Informed consent:}

Subjects who fulfilled the inclusion criteria were shown information sheet having details regarding the nature of study, and the drugs to be used. Subjects were given enough time to go through the study details mentioned in the information sheet. They were given the opportunity to ask any question and if they agree to participate in the study, they were asked to sign the informed consent form.

\section{Investigations:}

1. Routine investigations like complete blood picture, ESR, RBS and routine urine examination were done to exclude general diseases.

2. SGOT, SGPT, alkaline phosphatase, serum creatinine and blood urea were done before and after trial to assess the safety of test and control drug.

\section{Specific Investigations:}

Coagulation profile (BT, CT, PT, Platelet count), thyroid profile and pelvis ultra-sonography test were done to exclude coagulation disorders, thyroid dysfunction and pelvic pathology respectively.

\section{Intervention:}




\section{Criteria of Selection of Test Drug and Dry cupping:}

The test drug, Hulbaand dry cupping are in use since long time to relieve pain related to uterus. Hulbahas properties like musakkin(analgesic), mudirrehaiz wa bowl (emmenagogue, and diuretic), dafae tashannuj(anti spasmodic), muhallil(antiinflammatory), kasire riyah(carminative), and muwallide dum(haematinic). Dry cupping works on the principle of imalae mawad. ${ }^{23}$

\section{Test Drug: Orally}

Hulba (Trigonella foenurn graecum) was studied as a test drug, which was obtained from the local market of Deoband.

\section{Method of Administration and Dosage}

Orally: Fine powder of Hulba 3 gm was filled in the capsules and administered twice daily from $1^{\text {st }}$ to $3^{\text {rd }}$ day of menstruation for three consecutive cycles.

Locally: Dry cupping: Three medium size cups were applied below the umbilicus for 15 minutes on $1^{\text {st }}$ and $3^{\text {rd }}$ day of menstruation.

Duration of Treatment: Three months.

\section{Outcome Measurements:}

The primary outcomes were menstrual pain intensity, measured with well validated Visual Analogue Scale and safety of the test drug, evaluated by clinical examination and laboratory investigations. The secondary outcome variable was associated symptoms (fatigue, headache, anxiety, nausea and vomiting). Subjective assessment were done before and after the trial on the basis of 4 point scale ( 0 -none, 1 mild, $2=$ moderate, $3=$ severe).

\section{Assessment and Follow up During Study Period:}

The efficacy of the test drug and dry cupping were assessed by observing the change in the rating score of subjective and objective parameters. At- every visit after menstruation for three consecutive months of treatment and one month of follow up the subjects were asked about the improvement or worsening in their symptoms, which were recorded in the case record form. After completion of the trial, the pre and post treatment values were statistically analyzed and compared to evaluate the efficacy and safety of the treatment.

Adverse Effects Documentations: Adverse drug reactions were noted during or after treatment. Documentation: The records were submitted to the department after completion of study. Withdrawal Criteria: Failure to follow the protocol and the cases in which drug adverse reaction were noted. 


\section{RESULTS AND DISCUSSION}

A total no of 130 subjects were interrogated and screened for dysmenorrhoeain this study. Out of them 40 did not review and 90 were subjected to preliminary investigations in which 18 were excluded. 72 patients were randomly allocated in three groups, twenty in each group allowing $20 \%$ drop out. To observe the efficacy and safety, statistical analysis was done in all the three groups. The parameters were evaluated before and after the trial. (Fig. 1\& 2)

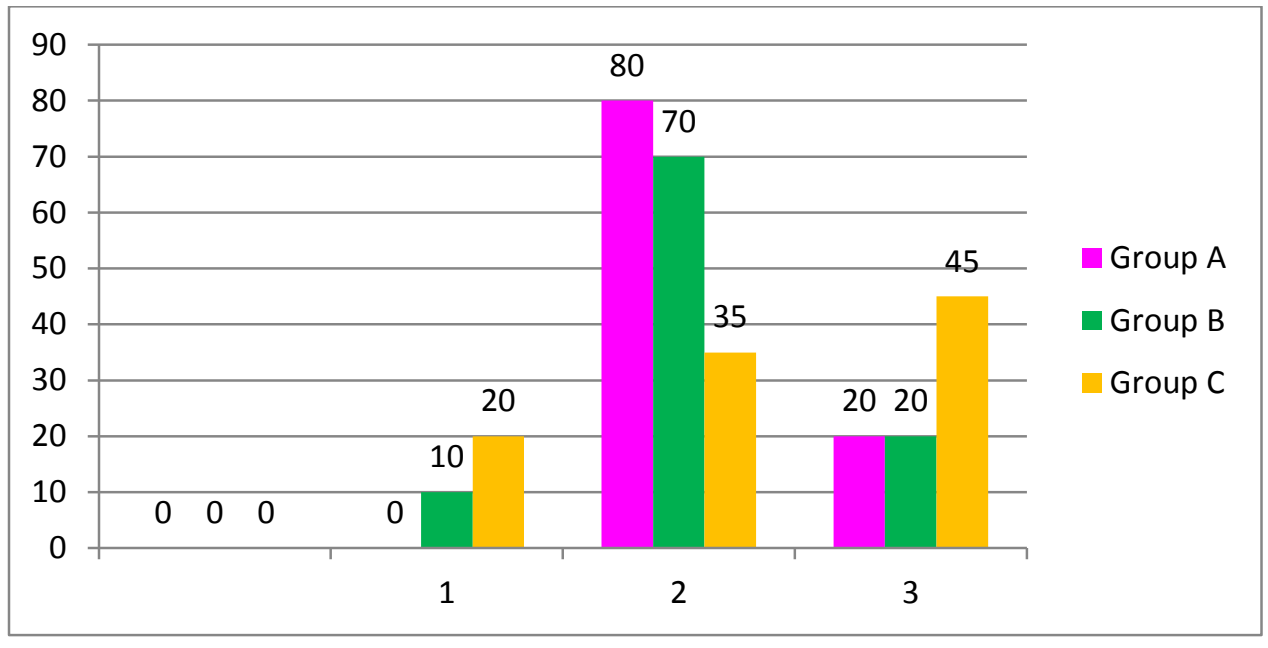

\section{Figure 1: Distribution of Subjects According to the Duration of Pain}

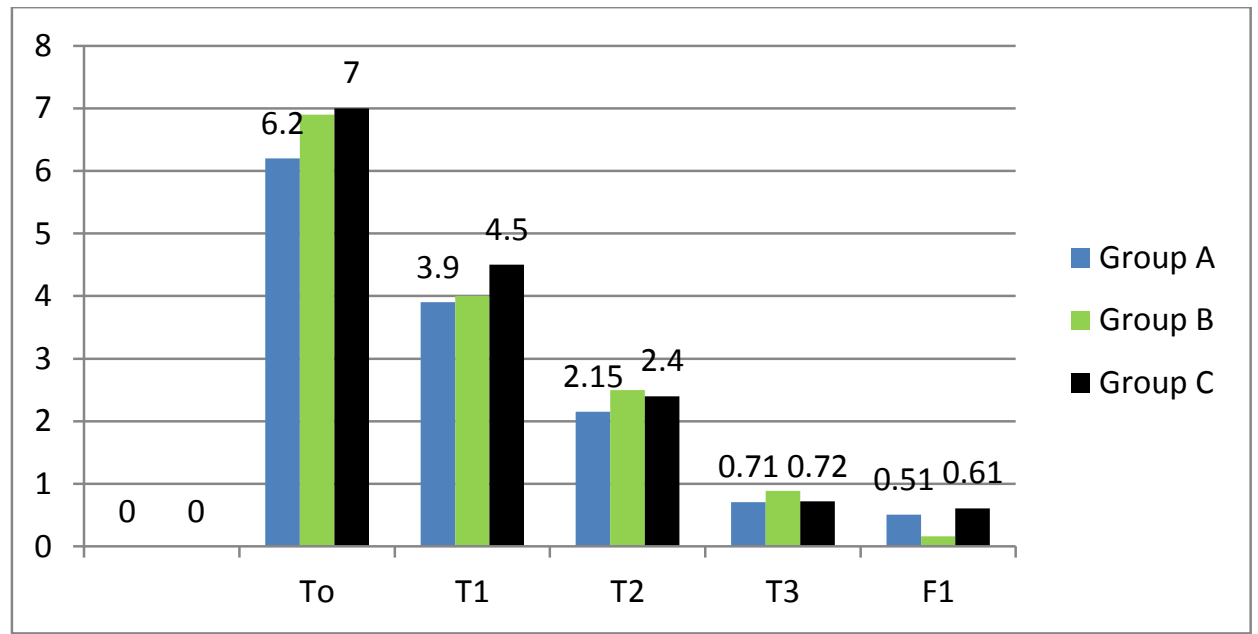

Figure 2: Comparison of Visual Analogue Scale for Lower Abdominal Pain in Three groups of subjects.

In the present simple randomized standard controlled study was conducted on 60 subjects, equally divided into three separate groups of A, B, C to assess the efficacy and safety of hulba and dry cupping in the management of Primary Dysmenrrhoea. Mefanamic acid which is a choice of drug for the management of Primary Dysmenrrhoeawas used as standard control. Till 
date, there are very limited studies documented on hulba and dry cupping in patients with dysmenorrhoea using well validated pain rating scale.

\section{Primary Outcomes}

Dry cupping works on the principle of imalae mawad(Diversion/shurtting of morbid matter/fluid) from the affected area. ${ }^{19}$ It is stated that shutting of blood flow away from the viscera results in relieving the congestion in the pelvic area, and suppresses the prostaglandins and release of beta endorphins producing endogenous analgesia. ${ }^{21}$ Likewise, on the same basis, it is hypothesized that dry cupping also suppresses the prostaglandins and release of beta endorphins producing analgesia as it shift the blood flow from the uterus. Hence, dry cupping was effective in relieving Primary Dysmenrrhoea. This proves the claim of ancient Unani physician that it relieves dysmenorrhoea, especially in young girls. ${ }^{19}$

\section{SUMMARY}

Hulba and dry cupping are in use since antiquity for dry cupping but validation and documentation are sparse. Thus, the present simple randomized standard controlled study was conducted to assess the efficacy and safety of hulba and dry cupping in its management. Hence more intensive and extensive studies are required to confirm the efficacy of test drug Hulba and dry cupping and then attempts should be taken to prove its efficacy and introduce at on large scale healthcare delivery system by using government agencies for improving general quality of life of adolescents and young menstruating women.

\section{CONCLUSION}

The present study which is single center, open labeled, simple randomized standard controlled, pre and post evaluation trial was conducted on sixty subjects to prove the efficacy and safety of hulba and dry cupping. Hulba was found to be as effective as mefanamic acid, whereas hulba with dry cupping was more efficacious than mefanamic acid in reducing pain intensity and agony along with overall improvement was noticed in other associated symptoms like nausea vomiting fatigue, headache etc.

No adverse effects have been observed either in the subjects of test group or standard group. The biochemical and safety parameters were within the normal range before and after trial, proving that all groups were safe. Majority of the subjects had balghami mizaj in this study. The presence of abnormal khilt balgham in the uterus is responsible for producing tashannuj. This confirms the claims of Unani physicians that primary dysmenorrhea caused by sue mizaj and ghalzate khilt. The prevalence of primary dysmenorrhoea in this study was observed in 
adolescents, .average age of menarche was 13 years with a predominant family history. It is observed that hulba with dry cupping was effective even after completion of the trial. In this study, Hulba was found to be efficacious. Because of its. Dafae tashannuj, dafae dard, mudirre haiz, mulatiff and muhallil properties. It is pharmacologically proved for its antiinflammatory, analgesic, diuretic, and immunomodulatory activities. These properties are attributed to the presence of saponins, tannins and flavonoids. It is suggested that dry cupping shurtts the blood flow from the uterus suppressing the prostaglandins and release of beta_ endorphins- producing analgesia. Therefore, dry cupping was effective ill relieving dysmen. Hence, further it is recommended in secondary dysmenorrhoea, large sample size for longer duration with scientific validation by estimating prostaglandin level in menstrual blood.

\section{ACKNOWLEDGEMENT:}

Author(s) acknowledges the concerned college, their teaching faculties, laboratory, IPD\& OPD staffs for their kind support. Thanks to the librarian to provide the books on time. Authors pay gratitude to the all the authors and writers whose work has been referenced and mentioned in this research article.

\section{REFERENCES}

1. Razi AB. Kitab Al Hawi. Vol IX. New Delhi: CCRUM; 2001: 20, 21, 29, 30, 31, 32, 33, $36,37,154,155,166$.

2. Qamri A. Ghana Mana. Tarjumae Minhajul Ilaj. New Delhi: CCRUM. 2008: 410.

3. Kabeeruddin M. Kulliyate Nafeesi. Lahore: Idarae Matbooate Sulemani; 481,714,715.

4. Kabeeruddin M. Kulliyate Qanoon. Karachi: Shaikh Mohammed Basheer and Sons; 348349.

5. Masako K, Togashi K and Kido et.al. D: smenorrhea: Evaluation with Cine-ModeDisplay MR Imaging Initial Experience. RSNA: 2005; 235:124-131.

6. Khan A. Haziq. Pakistan: MaiLa publishing Company; 1983: 467-469.

7. Jeelani G. Makhzanul Hikmat. New Delhi: Aijaz Publishing House; 1996: 786-793.

8. Ibn Sina. Al Qanoon Fit Tib. Vol. IL (Urdu translation by Kantoori GH); New Delhi: Idara Kitabul Shifa; 2007: 227, 260, 291, 312, 331, 340, 342, 374.

9. Dorn L D, Negrif S. Huang B et. Al Menstrual Symptoms in Adolescent Girls: Association With Smoking, Depressive Symptoms, and Anxiety. Journal of Adolescent Health: 2009; 44:237-243. 
10. Dawood Y M. Dysmenorrhoea. Glob Libr Women's med: (ISSN: 1756-2228) 2008: Accessed on 28-9-10. DOI 10.3843/GLOWM.10009.

11. Edward Q J, Frederick Z P. Current Therapy in Obstetrics \& Gynaeeolooy. $5^{\text {th }}$ ed. London:W.B.Saunders Company;2000:31-32

12. Edw ds J E, Moore R A, McQuay H J. Rofecoxib for Dysmenorrhoea: Me a-analysis using individual patients' data. BMC Women's health: 2004:4(5):1-7.

13. Shbabnanda. Hijama or Cupping. Therapies- ways of Treatment. www.Shbabnanda.com/fit/=. Assessed on 25-12-10.

14. Anjurn N, Jamil S, Hannan A, Jamal A, Bilal A. Clinical efficacy of Hijamat (Cupping) in Waja-ul-Mufasil (Osteoarthritis). Indian Journal of Traditional Knowledge. Oct 2005;4(4):412-415.

15. Wood Tiger Massage, LLC. www.woodtigermassage.com/cupping.php.Accessed on 25-12-10.

16. Ibn Rushd. Kitabul Kulliyat. Vol II. New Delhi:CCRUM, 1987:56, $87,114,115,116,129,194,210,426$.

17. Kabeeruddin M. Kulliyate Qanoon. Karachi: Shaikh Mohammed Basheer and Sons; 340349.

18. Razi. AB. Kitab Al Hawi. Vol VI. New Delhi:. CCRUM;..1999: 11-13.

19. Shah M H...The .general principles of Avicenna's Cannon of Medicine. Vol. 1, $2^{\text {nd }}$ ed. Karachi: Interservicepresco; 1998:204, 408.

20. Hamdani H. Ilaj Bil Tadbeer. New Delhi: Aijaz Publishing House: 62.

21. Wallis LA, Kasper AS, Brown W, Gordon G, Oril R, Barbo D et al. Textbook of women's Health. Philadelphia: Lippincott Raven Publishers; 1998: 471.

\section{AJPHR is}

Peer-reviewed

monthly

Rapid publication

Submit your next manuscript at editor@ajphr.com / editor.ajphr@gmail.com 